\title{
A consolidação da eletrificação pela Copel na cidade de Maringá-PR (1956-1969): conflitos e repercussão no território e na sociedade
}

Leandro Cassimiro Barbosa leonardo.cb@gmail.com Universidade Estadual de Maringá, Maringá, Paraná, Brasil

\section{Fabíola Castelo de Souza}

\section{Cordovil}

fabiolacordovil@gmail.com

Universidade Estadual de Maringá, Maringá, Paraná, Brasil

\section{Thaylise Marega Souza}

thay marega@hotmail.com

Universidade Estadual de Maringá, Maringá, Paraná, Brasil

\section{Murilo Savaris}

murilo.savaris@outlook.com Universidade Estadual de Maringá Maringá, Paraná, Brasil

\section{Stefani Massa}

stefanimassabia@gmail.com Universidade Estadual de Maringá, Maringá, Paraná, Brasil

\begin{abstract}
RESUMO
A cidade de Maringá, implantada em 1947, é fruto de um plano de colonização empreendido por uma companhia colonizadora privada, na porção Norte do Paraná. O fato de esta companhia não implantar infraestruturas e serviços básicos para o seu funcionamento trouxe uma série de dificuldades para a urbe, que crescia em ritmo acelerado. A tentativa de solucionar o acesso à eletrificação se deu com a instalação, em 1956, da recém-criada Companhia Paranaense de Energia (COPEL). O objetivo deste estudo consiste em analisar o processo de estruturação da COPEL em Maringá, entre 1956-1969, entendendo a lógica de implantação da eletrificação e o seuimpacto na sociedade maringaense. A confrontação de diversas fontes documentais mostrou que a instalação da concessionária estadual se deu de forma conflituosa, tendo que superar diversos obstáculos como:dificuldades técnicas na geração de energia, adoção de racionamento, estruturação da rede de distribuição, críticas ao elevado custo do serviço, além de grande pressão popular e do poder municipal para melhora do atendimento. Tais dificuldades, porém, contribuíram para a estruturação da COPEL que, anos mais tarde, tornar-se-ia o ator hegemônico na eletrificação do paranaense.
\end{abstract}

PALAVRAS-CHAVE:Energia elétrica;redes técnicas;urbanização. 


\section{INTRODUÇÃO}

As cidades - resultado da complexa interação de fatores sociais, culturais, políticos e econômicos -são fortemente influenciadas pela tecnologia disponível, aplicada em sua conformação. Contudo, ainda que a análise da evolução técnica possa explicar o processo de desenvolvimento das infraestruturas, ela, por si só, é insuficiente para se entender o desenvolvimento histórico das cidades, pelo fato de este processo ser regido por fatores como investimentos, políticas públicas, conjuntura econômica, geografia do local etc., que torna o processo não linear (TARR, 1984). O estudo da conformação das redes técnicas no território"Traducebienalgunos tipos de relaciones espacio/tiempo/información/território característicos de las sociedades modernas" (DUPUY, 1998, p.18), sendo assim análise importante para a contextualização do desenvolvimento urbano.

O processo de eletrificação nas cidades, que se deu, principalmente, a partir de 1880, impulsionado pela urbanização crescente da sociedade, trouxe grandes transformações para o cotidiano dos moradores e impactou na qualidade de vida destes. De acordo com Ferreira (2013), a eletrificação proporcionou uma espécie de extensão e compressão do tempo vivido nas cidades, isso porque promoveu uma aceleração da mobilidade com relação aos sistemas de transporte, e permitiu que as atividades diárias, antes regidas pelo amanhecer e pelo anoitecer, se estendessem por mais tempo. A iluminação pública trouxe uma sensação de segurança, permitindo que houvesse "vida noturna". Para Capel (2015), a iluminação pública, além de permitir a conquista da noite, foi um fator decisivo para o desenvolvimento industrial e para a libertação das mulheres no que tange aos fardos da vida doméstica, à medida que se introduziram os eletrodomésticos.

A eletrificação nas cidades brasileiras tem seu início nas últimas décadas do século XIX, principalmente nos grandes centros, estando inicialmente voltada para atender demandas dos serviços públicos e de iluminação urbana. $\mathrm{Na}$ primeira metade do século $X X$, o serviço se populariza no Brasil, tendo como importante marco o Código de Águas de 1934, que irá versar sobre a propriedade das águas, estabelecendo a União como a única entidade com poder de concessão para a exploração hídrica. No cenário paranaense, Curitiba se mostra pioneira no estabelecimento da eletrificação, com o contrato firmado em 1890 com a Companhia de Água e Luz do Estado de São Paulo, para a iluminação da cidade (COPEL, 2016; RECCO, 2007). Contudo, nas porções de colonização mais recente do estado - como a região Norte, onde se situa Maringá -, a energia elétrica demorou a se estabelecer.

A cidade de Maringá, localizada no noroeste do Paraná, foi implantada ex novo por meio de um grande empreendimento de colonização realizado pela Companhia de Terras Norte do Paraná (CTNP) que, em 1951, tornou-se Companhia Melhoramentos Norte do Paraná (CNMP) (CMNP, 1975). Tendo como objetivo a venda de glebas rurais destinadas, principalmente, ao plantio de café, a CTNP iniciou a colonização da região norte do estado em 1925, em uma área de 546.078 alqueires paulistas onde, além do parcelamento rural, implantou uma rede de mais de 60 cidades, entre 1930 e 1960. O plano regional de ocupação traçado adotou, como linha mestra, o eixo rodoferroviário, que acompanhava o espigão, onde se estabeleceram quatro cidades polo - Londrina (1930), Maringá 
(1947), Cianorte (1953) e Umuarama (1955) - distantes 100 km entre si, com núcleos urbanos de apoio rural, menores, entre estas, e em eixos secundários(Figura 1) (REGO e MENGUETTI, 2008).

Pensada para desempenhar um papel de polo regional, a cidade de Maringá, oficialmente inaugurada em 1947, recebeu um moderno traçado urbanístico, de autoria do engenheiro paulistano Jorge de Macedo Vieira. Segundo Cordovil e Andrade (2008), o traçado proposto por Vieira apresenta um hibridismo de ideários urbanísticos, que perpassa os conceitos de Howard, Unwin, Hegemann e Brunner. O processo de ocupação da cidade ocorreu de maneira expressiva, chegando a 38.588 habitantes em 1950, e em 1970 já contava com 121.374 habitantes, sendo mais de 100.000 na área urbana (IBGE, 1950; 1970).

Figura 1: Área colonizada pela CTNP/CMNP (verde escuro), com destaque para Maringá (amarelo) e as demais cidades polo (vermelho)

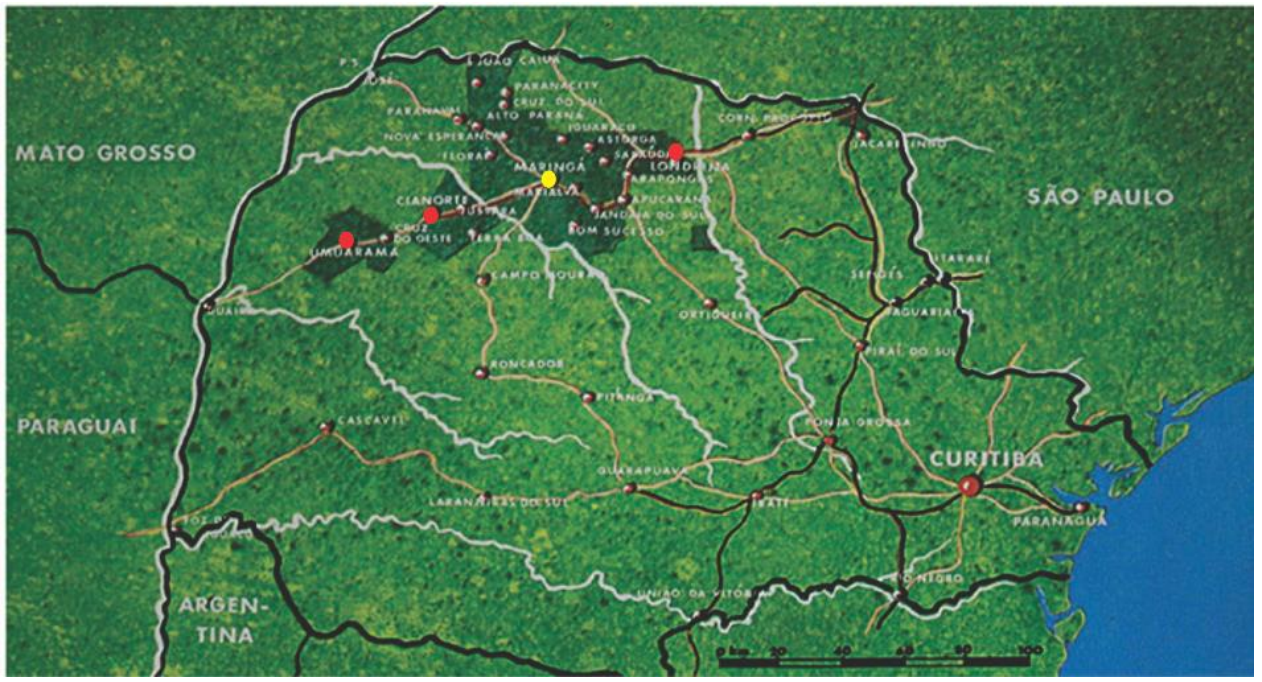

Fonte: CMNP, 1975 - Adaptado pelos autores.

Esse rápido crescimento populacional em um curto período, aliado à falta de recursos financeiros arrecadados pela municipalidade, fazia com que esta não conseguisse realizar os serviços de infraestrutura de forma satisfatória, como foi o caso do abastecimento de energia, o que gerava transtornos à vida dos maringaenses.De acordo com Luz (1997), a CMNP deixava a implantação das infraestruturas a cargo das incipientes municipalidades, limitando-se apenas ao traçado dos arruamentos, à divisão dos lotes e à colocação dos meios fios nos núcleos urbanos que se implantavam. Isso acontecia porque, no âmbito federal, somente em 1979,com a Lei Lehmann1, tornou-se obrigatória a implantação de infraestrutura pelos loteadores em seus empreendimentos. O descaso da CMNP com o provimento de infraestrutura contrastava com a ideia de modernidade propagandeada pela companhia, em razão do plano urbanístico de Macedo Vieira (BARBOSA, 2016).

1 Lei Lehmann (Lei Federal no 6766/79, alterada pela Lei Federal n $\left.{ }^{\circ} 11.445 / 2007\right)$ : regula a atividade de parcelamento do solo urbano em todo o território nacional. $\mathrm{O} \S 4^{\circ}$ dessa lei considera como lote o terreno servido de infraestrutura básica, cujas dimensões atendam aos índices urbanísticos definidos pelo plano diretor ou pela lei municipal para a zona em que se situe. O $\$ 5^{\circ}$ define infraestrutura básica como os equipamentos urbanos de escoamento das águas pluviais; iluminação pública; redes Págna esgoto sanitário e abastecimento de água potável; de energia elétrica pública e domiciliar, e as vias de circulação, pavimentadas ou não. 
O objetivo deste estudo consiste em analisar o processo de estruturação da COPEL em Maringá, entre 1956 e1969, entendendo a lógica de implantação da eletrificação e seuimpacto na sociedade maringaense. O recorte temporal escolhido compreende o início de atuação da COPEL em Maringá (1956) até a consolidação do sistema de abastecimento (1969), pouco após a vinda do sistema de alta tensão, oriundo da Usina de Salto Grande. Devido às diferentes formas de abastecimento e aos diferentes impactos gerados à população, a análise se divide em dois subperíodos: 1956-1962 - fase dos motores a diesel e falta de energia frente à demanda; 1962-1969 - fase da energia de alta tensão e alto custo do serviço.

A atuação inicial da COPEL no estado do Paraná e a lógica de implantação da eletrificação, nos anos iniciais da cidade de Maringá, são temas pouco explorados pela historiografia urbana local. A instalação pioneira da concessionária estadual num núcleo urbano nascente, carente de infraestruturas, mas que apresentava altas taxas de crescimento populacional, foi um importante desafio para sua estruturação, contribuindo para que, anos mais tarde, se tornasse o ator hegemônico na eletrificação paranaense.

Assim, o desenvolvimento da pesquisa foi pautado na análise de dados primários e secundários disponíveis. Dentre os dados primários, a principal fonte documental utilizada foi o periódico 0 Jornal de Maringá2, de veiculação diária que, com bastante frequência, apresentava notícias sobre a COPEL, além de investimentos e problemas no sistema de eletrificação da cidade e as reações da sociedade perante os acontecimentos. As informações obtidas a partir da análise do periódico foram complementadas e confrontadas com outras fontes documentais levantadas, sendo estas: fotos históricas do município3 para análise das porções servidas pela eletrificação; e o Diagnóstico do Plano Diretor de 1967, por meio do qual se pôde observar o panorama do serviço de abastecimento de energia, já no período final do recorte temporal estabelecido. Os dados secundários consistiram na revisão da literatura de trabalhos científicos, de abordagem historiográfica, do processo de construção da cidade de Maringá sob diversos aspectos, e do processo de eletrificação do estado do Paraná e do município de Maringá.

\section{O CENÁRIO DA ELETRIFICAÇÃO DO PARANÁ E DE MARINGÁ ANTES DA CRIAÇÃO DA COPEL}

A história da energia elétrica no Paraná teve sua origem na capital Curitiba, quando, em 09 de setembro de 1890, tem-se o contrato firmado entre a Companhia de Água e Luz do Estado de São Paulo e o então presidente da Intendência Municipal de Curitiba, Dr. Vicente Machado, com a finalidade de iluminar a cidade. Em 1901, instala-se, num terreno locado na Avenida Capanema, a primeira usina termelétrica na capital, que operava inicialmente

\footnotetext{
${ }^{2}$ O Jornal de Maringá foi o primeiro impresso da cidade de Maringá, criado em 18 de junho de 1950. Em 1991, mudou de nome paraO Jornal do Povo e, com esse título, ainda circula na cidade. Foram analisadas as edições entre os anos de 1960 e 1970, disponíveis no acervo da Gerência de Patrimônio Histórico da Prefeitura Municipal de Maringá (PMM).

${ }^{3}$ Acervos da Gerência de Patrimônio Histórico da Prefeitura Municipal de Maringá (PMM); do Museu da Bacia do Paraná; da

Pápinablioteca Pública Municipal de Maringá; dos Departamentos de História e de Arquitetura e Urbanismo da Universidade Estadual de Maringá; e do Arquivo Histórico Municipal.
} 
com dois conjuntos geradores de 200 HPs cada.Paranaguá foi a segunda cidade no estado a contar com os benefícios da eletrificação, em 1902, por meio da família Blitzkow, que implantou um sistema de geração com dois grupos a vapor, de 52 Kw. Em seguida, foi a vez de Ponta Grossa (1904) e União da Vitória (1916) implantarem este serviço (COPEL, 2016).

Com o respaldo do Código de Águas (instituído pelo Decreto-Lei $n^{\circ} 24.463$, de 10 de julho de 1934) e do Conselho Nacional de Águas e Energia Elétrica (Lei $n^{\circ} 1.285$ de 1939), o Poder Público passa a coordenar o setor energético, que até então ficava totalmente dependente da iniciativa privada. Nesse contexto, é digno de ressalva o ano de 1947, com o surgimento do Serviço de Energia Elétrica do Paraná, que, no ano seguinte,tornar-se-iao Departamento de Águas e Energia Elétrica (DAEE), contando com o apoio do Plano Nacional de Eletrificação (COPEL, 2016).

Junto com a criação do DAEE, em 1948, é elaborado o Plano de Eletrificação Paranaense, prevendo os investimentos necessários para os sistemas de eletrificação do estado. Em 1952, para a viabilização do plano, estipularam-se duas etapas de investimentos: a primeira prevendo a execução de hidrelétricas de pequeno porte (Cavernoso, Caiacanca e Laranjinha); e a segunda, dependente de financiamentos, que previa a construção das hidrelétricas de maior porte (Capivari-Cachoeira, Tibagi, Carvalhópolis) e da termelétrica de Figueiras (COPEL, 2016).Como colocado por Recco (2007), na prática a implantação dos sistemas privilegiou a porção leste e os campos gerais do Paraná - incluindo, assim, a capital Curitiba -, que receberam energia das hidrelétricas no momento em que cidades da porção norte recebiam conjuntos geradores diesel-elétricos em caráter emergencial.

Algumas cidades do estado eram abastecidas por empresas privadas, responsáveis pela geração e distribuição de energia. Este era o caso de Londrina e outras, na região, abastecidas pela Empresa Elétrica de Londrina S.A, ligada à CTNP/CMNP, que gerava energia através de pequenas hidrelétricas:a do ribeirão Cambezinho, inaugurada em 1939, que produzia 0,225 megawatts; a Usina Três Bocas, que entrou em funcionamento em 1943, com uma produção de 0,45 megawatts em 1949; e a Usina de Apucaraninha, cuja produção chegava a 9,5 megawatts (BERGOC, 2012). Sendo o âmbito de ação de tais empresas estritamente local, estas não reuniam as vantagens das interligações e de um sistema unificado de geração e distribuição em todo o Estado (COPEL, 2016).

Este cenário começa a se alterarcom a criação da Companhia Paranaense de Energia Elétrica (COPEL), por meio do Decreto $n^{\circ} 14.947$, de 26 de outubro de 1954, assinado pelo então governador Bento Munhoz da Rocha Netto. A partir daí, gradativamente a COPEL irá assumiras ações governamentais de planejamento, construção e exploração dos sistemas de produção, transmissão, transformação, distribuição e comércio de energia elétrica, que até então eram responsabilidade do DAEE, das prefeituras e das concessionárias particulares. $\mathrm{O}$ primeiro município a receber os serviços da empresa estadual será Maringá, no ano de 1956.

Como vimos, Maringá, já nos primeiros anos de sua origem, apresentou uma rápida ocupação territorial. A primeira ocupação urbana em seu território se deu com a implantação de um núcleo provisório, chamado "Maringá velho", instalado em 1942 como base de apoio para a abertura da cidade planejada, inaugurada 
em 1947. Em 1950, com população de quase 40.000 habitantes, a cidade já possuía cerca de $60 \%$ de sua área planejadaestabelecida, conformados pela implantação integral da sua área central (Zona 1), e Zonas 2 e 3; sendo abertas parcialmente as zonas 4, 6, 7, Zona de Armazéns e uma pequena parcela da Zona 10 (industrial) (Figura 2) (BARBOSA, 2016).

Esse crescimento urbano proeminente propiciava uma grande demanda por energia elétrica, fator determinante para a manutenção do desenvolvimento da cidade e para a garantia de sucesso como empreendimento imobiliário da CMNP. Todavia, devido às características geomorfológicas de relevo - plano do tipo coxilhado, onde predomina o perfil suave, formado por destacáveis porções com baixas declividades -e ao fato dea cidade ser locada sobre o principal divisor de águas da região - que faz com que os cursos d’água que nascem na zona urbana apresentem dimensões e volume reduzido (MENEGUETTI, 2007) - , o cenário hídrico era desfavorável para a instalação e a produção de energia hidrelétrica, diferentemente do ocorrido em Londrina, cidade abastecida por pequenas hidrelétricas de propriedade da CMNP.

Desta forma, Maringá teve que adotar, como solução para o problema da energia, medidas paliativas de geração de energia que se mostravam insuficientes frente à demanda crescente. A primeira solução empreendida pela municipalidade foi a instalação de quatro motores diesel usados, com a potência de 2.080 cavalos e $288 \mathrm{Kw}$ cada, de origem alemã, instalados pela UTIL Companhia Brasileira de Planejamento, nas margens do córrego Mandacaru. Tais equipamentos foram obtidos, em 1952, pelo prefeito maringaense em exercício, Inocente Vilanova Júnior, devido à sua influência política na capital Curitiba (RECCO, 2007).

Figura 2: Adensamento Construtivo - Maringá 1953

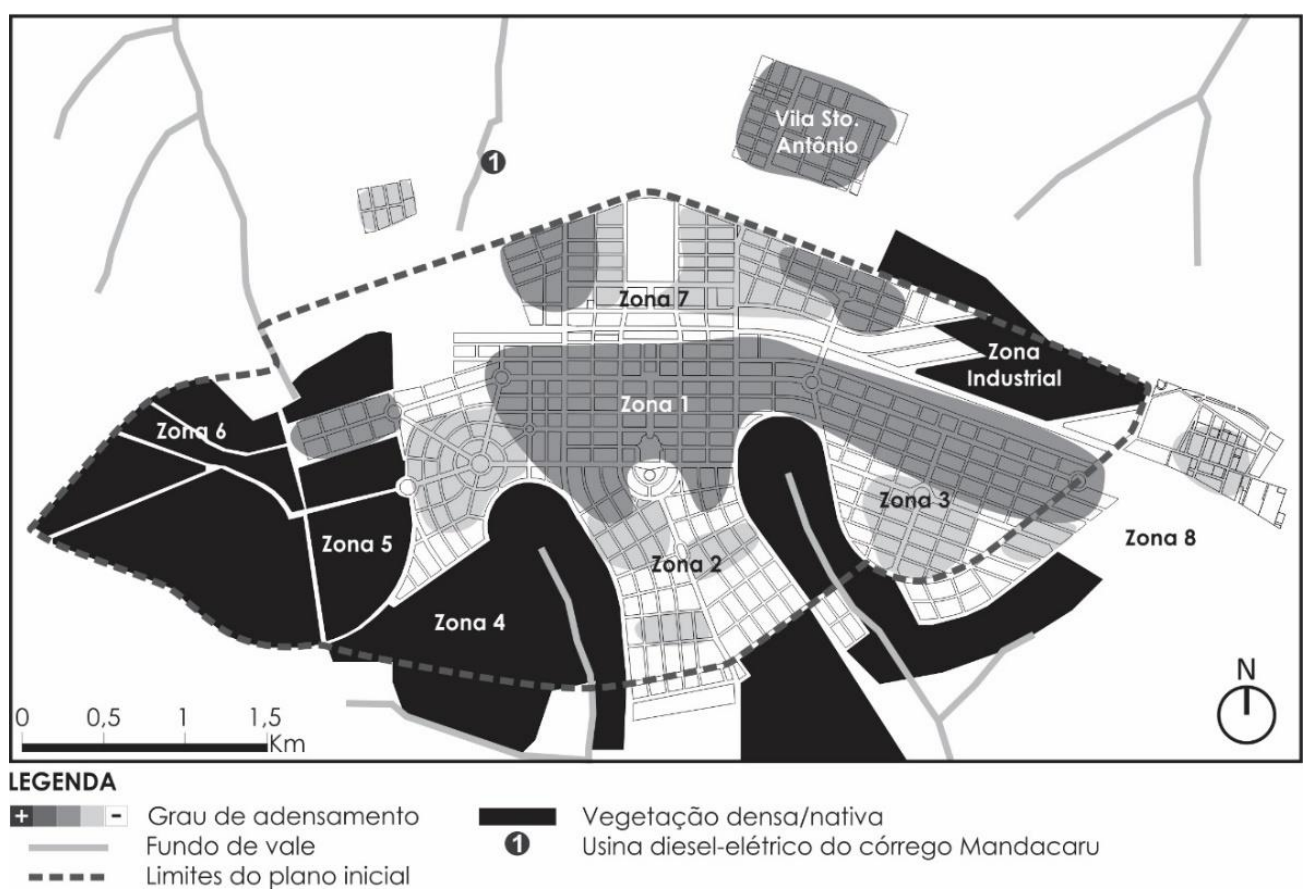

Fonte: DEC/UEM - Laboratório de Aerofotogrametria - Levantamento Aerofotogramétrico de 1953 - Adaptado pelos autores. 
adotar medidas particulares para superar o déficit de energia: para os moradores, as velas e lampiões eram de uso obrigatório ao escurecer (RECCO, 2007);já os maiores estabelecimentos consumidores, como grandes comércios, hospitais e hotéis, utilizavam pequenos geradores particulares a diesel, sendo que alguns pioneiros distribuíam precariamente a energia excedente para seus vizinhos (FERNANDO, 2012). Este foi o cenário encontrado pela COPEL ao assumir os serviços de eletrificação em Maringá, em 1956, estendendo sua atuação, na sequência, para cidades vizinhas que estavam sob responsabilidade do DAEE, a saber: Apucarana, Campo Mourão, Mandaguaçu, Pirapó e Cambira.

\section{A CRIAÇÃO DA COPEL E SUA INSTALAÇÃO PIONEIRA EM MARINGÁ}

A análise do processo de atuação da COPEL na cidade de Maringá foi dividida em duas fases, delimitadas em razão da forma de geração de energia elétrica e do impacto do serviço na sociedade. Assim, a 1ạ fase compreende o período de 1956 a 1962, e é marcada pela geração por meio dos motores diesel-elétricos que não conseguiam suprir a demanda, resultando num serviço bastante precário para a população; a 2a fase se dá entre 1962 e 1969, marcada pela vinda da eletrificação de alta tensão da Usina Hidrelétrica de Salto Grande, solução definitiva para resolver o problema da geração, mas que não cessou a relação conflituosa com os habitantes, devido à inconsistência do sistema de cobrança e do alto custo do serviço.

O foco desta análiseestáno impacto da evolução tecnológica napopulaçãoque, "[...] embora não determine a evolução histórica e a transformação social, a tecnologia (ou sua falta) incorpora a capacidade de transformação das sociedades" (CASTELLS, 2005, p.44). Assim, a tecnologia não determina a sociedade, damesma forma que a sociedade não determina o curso das transformaçõestecnológicas;esta relação é resultado final de um complexo padrão interativo, queenvolve aspectos como criatividade, iniciativa empreendedora, descobertacientífica, inovação tecnológica e aplicações sociais (CASTELLS, 2005).

1aFase (1956-1962): início de atuação da COPEL e a falta de energia frente à demanda

A partir de 1956, o gerenciamento da usina de motores a diesel do córrego Mandacaru, instalados em 1952, fica a cargo da COPEL e, segundo Cordovil e Barbosa (2015), teve o início de sua atuação marcado por uma série de dificuldade técnicas e financeiras. Funcionando desde o início com quatro motores a diesel usados, quando a empresa do estado chegou a Maringá dois deles estavam com os mancais fundidos, o que resultava em um péssimo serviço da COPEL na cidade, onde racionamentos e quedas de energia eram comuns. Nesse período, com uma população urbana de 15.000 habitantes e 1.700 ligações feitas através de postes de madeira e fios de diâmetros inferiores à necessidade, Maringá dispunha do funcionamento dos motores que se dava apenas das 7 às $11 \mathrm{~h} 30$ e das 18 às 22 horas. Durante o dia, priorizava-se o atendimento da área central da cidade e os equipamentos essenciais, como os hospitais. Os bairros eram servidos numa espécie de rodízio, recebendo energia por um período de 6 a 
8 horas por dia. Durante a noite, o atendimento concentrava-se na iluminação pública e em locais como o Grande Hotel e o cinema (SCHWABE, 2014). Mesmo com a aquisição de um quinto motor de $420 \mathrm{Kw}$, em 1957, a situação permaneceu crítica: em 1960, apenas três dos cinco motores estacionários a diesel estavam operando, impondo dificuldades à população que crescia em ritmo acelerado (RECCO, 2007). A figura 3 ilustra a instalação dos postes (em madeira) e da iluminação pública na Av. Brasil, principal via comercial da cidade à época, no início da década de 1950.

Figura 3: Instalação dos postes e iluminação pública na Av. Brasil, início da década de 1950

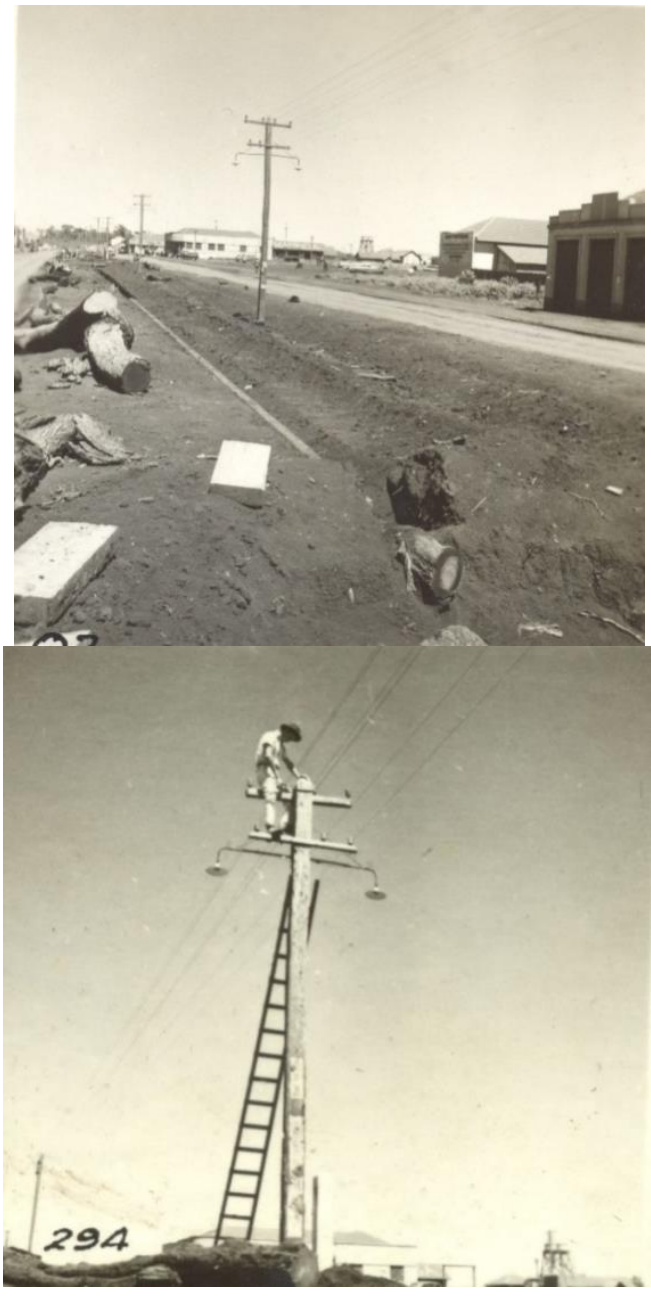

Fonte: Acervo do Museu da Bacia do Paraná.

Com base nas notícias veiculadas pelo O Jornal de Maringá (23 e 29 jul. 1960), é observado que a deficiência no abastecimento de energia atrasava o crescimento econômico da cidade, pois o racionamento trazia prejuízos à indústria, ao comércio, e à população em geral. Assim, em 23 de julho de 1960, graças às ações da Associação Comercial, dos poderes públicos e do candidato à prefeitura, João Paulino Vieira Filho, chegaram em Maringá, como forma de minorar o problema da COPEL, dois novos motores que, no entanto, entrariam em funcionamento apenas no início de 1961. Além disso, também seria feita a recuperação dos motores que estavam em colapso, o que supriria a necessidade das residências e das pequenas indústrias de Maringá. A chegada dos dois novos motores foi comemorada pela população que, neste mesmo mês, passou por 
duas situações graves, de racionamento: a primeira devido a problemas em uma das turbinas do gerador de maior potência da COPEL, que motivou uma queda de $60 \%$ na capacidade de fornecimento de energia elétrica; e a segunda por conta de um engrupamento em um dos pistões, que levou dois dias para ser solucionado (O Jornal de Maringá, 23 e 29 jul. 1960).

Em 11 dezembro de 1960, após noticiar mais um episódio de queda de energia, O Jornal de Maringá informava que a COPEL havia começado a extensão de sua rede à Vila Operária, indagando: "mas se nem aqui na cidade ela pode atender como será para os moradores daquele bairro de trabalho?" (O Jornal de Maringá, 11 dez. 1960). No início de 1961, a situação da Companhia, na cidade, mostrava-se bastante grave, como descrito pela publicação deO Jornal de Maringá (7 fev. 1961), que afirmava que os motores da COPEL não serviam mais, pois estavam "velhos, quebrados, estragados e mal cuidados", e se os recursos prometidos pelo Governador Ney Braga a Maringá não chegassem rapidamente, a passividade da população poderia acabar, pois "ninguém sabe o que pode fazer um povo indignado e com muita razão".

Em entrevista a O Jornal de Maringá (11 fev. 1961), o engenheiro civil Antônio Eriberto Schwabe, que ficou à frente da COPEL, em Maringá e região, de agosto de 1960 a janeiro de 1964, admitiu que os motores da empresa estavam realmente gastos, e afirmou que concentrou todos os seus funcionários na usina do córrego Mandacaru, a fim de terminar, o quanto antes, o serviço do novo motor que traria um reforço de 1.600 cavalos para Maringá. Em novembro de 1961, devido a uma pane no grupo dos velhos motores da usina do córrego Mandacaru, constituída agora por oito motores, noticiava-se novo episódio de falta de energia elétrica (O Jornal de Maringá, 18 nov. 1961).

Além da insuficiência de energia para o abastecimento, a COPEL também apresentava problemas na cobrança das contas: por não dispor de meios para efetuá-las com rapidez, a empresa cobrava juros pelo atraso no pagamento, o que gerava revolta na população, que não era culpada pela situação. Sobre esse tema, tramitava na Câmara Municipal de Maringá um requerimento propondo que as contas pudessem ser pagas em Banco, a fim de facilitar a vida dos contribuintes e evitando filas (O Jornal de Maringá, 21 fev. 1961).

De acordo com Cordovil e Barbosa (2015), diante da incapacidade de se estabelecer uma solução definitiva de eletrificação através da usina do córrego Mandacaru, a população pressionava os órgãos públicos afim de que uma solução realmente definitiva fosse tomada. A solução encontrada foi a utilização da energia produzida pela Usina Salto Grande, o que ocorreria a partir de 1962. Porém, antes disso, em 20 de novembro de 1961, foi tomada uma medida emergencial por meio da qual Maringá recebeu, em seu sistema de eletrificação, o reforço de 3 mil Kw da USELPA - Usinas Elétricas do Paranapanema S. A., através de uma linha transmissora construída em tempo recorde pela COPEL. Com esse reforço, a potência do município chegou a $5 \mathrm{mil} \mathrm{Kw}$, sendo quase totalmente superado o regime de racionamento, antes feito em $3 / 4$ da cidade. Além do reforço, dentro de um programa que visava à distribuição de energia mais farta e barata a toda região entre Londrina e Paranavaí -onde está compreendida Maringá -a COPEL previa, para o ano seguinte, a ligação de uma cota maior, e já vinha trabalhando na construção de outra linha de transmissão de 136 mil volts (O Jornal de Maringá, 21 nov. 1961). 
A necessidade de uma solução para o problema da eletrificação dava-se devido ao acelerado ritmo de crescimento apresentado por Maringá que, na década de 1960, se afirmava como polo regional e dava os primeiros passos do seu processo de verticalização (BARBOSA, 2016; MENDES,1992). Segundo o censo do IBGE de 1960, Maringá contava com uma população total de 104.131 habitantes, dos quais 47.592 viviam na área urbana e 56.539 na área rural. Esses números revelam o grande crescimento da população urbana da cidade que, em apenas dez anos, teve um aumento de cerca de 40 mil habitantes. 0 maior número de habitantes vivendo na área urbana levou a um aumento do grau de adensamento na área planejada, especialmente nas zonas 1, 3 e 7, e fomentava a expansão urbana por meio da adição de novos loteamentos (Figura 4).

Figura 4: Adensamento Construtivo - Maringá 1963

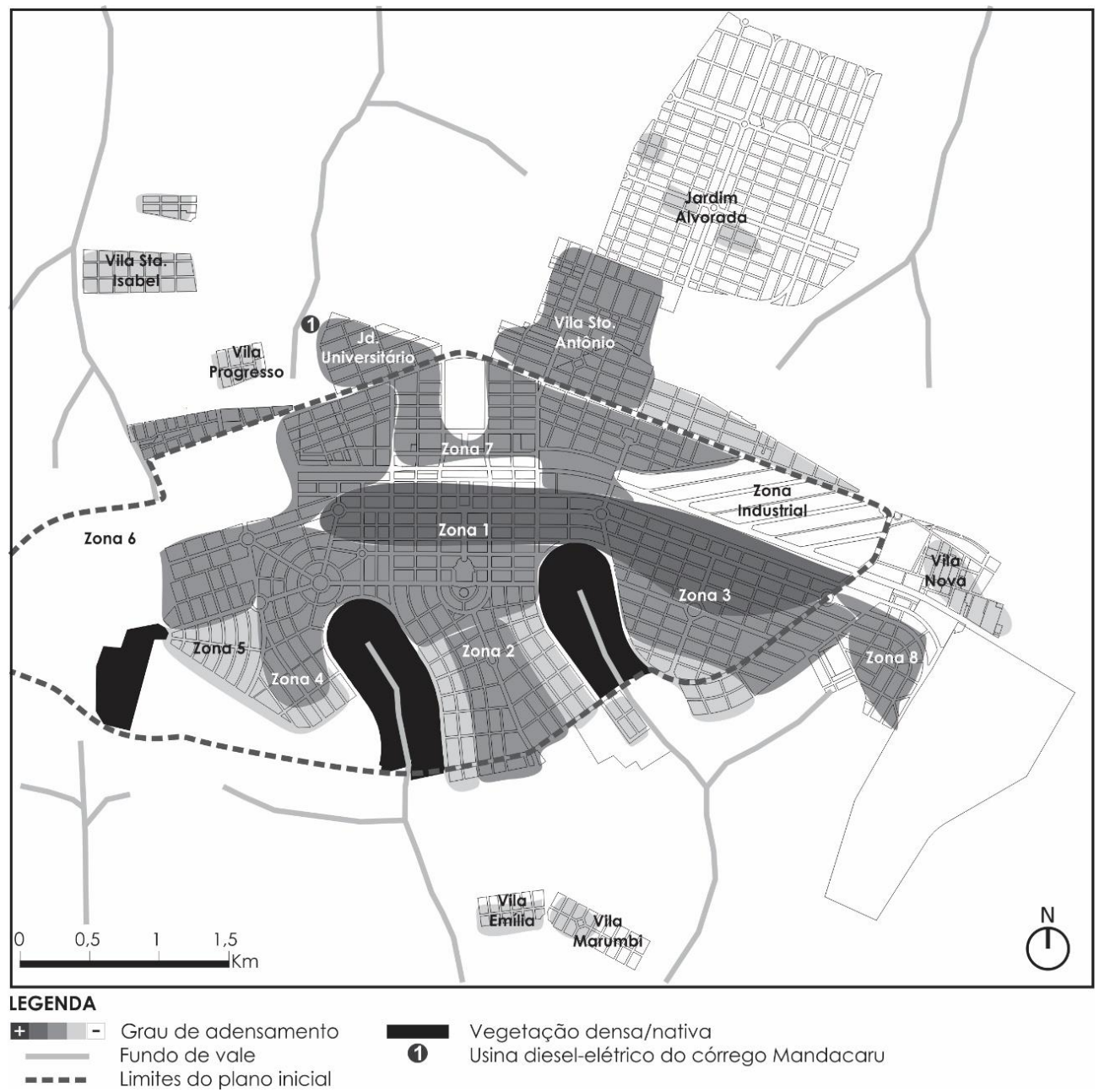

Fonte: DEC/UEM - Laboratório de Aerofotogrametria - Levantamento Aerofotogramétrico de 1963 - Adaptado pelos autores.

Em 1963, Maringá já possuía aproximadamente $78 \%$ de sua área planejada estabelecida, restando ainda porções das zonas 4,5 e 6 , que se situavam próximas a Maringá Velho. Porém, segundo Barbosa (2016), o que chama atenção, neste período, é a expressiva expansão pós-plano para o norte da cidade, principalmente com o loteamento da Vila Morangueira (1961) e do Jardim Alvorada (1962), os quais receberam, nesta década, diversas iniciativas de habitação popular. Neste momento, já haviam sido aprovados pela prefeitura 11 
novos bairros fora do limite da área planejada, de acordo com dados da Prefeitura Municipal de Maringá, apresentando padrões urbanísticos e infraestrutura inferiores aos do plano inicial, sendo uma alternativa à população de menor renda, frente à valorização dos lotes na área do plano inicial (BARBOSA, 2016).

Desta forma, este primeiro momento de atuação da COPEL na cidade de Maringá (1956-1962) representou poucos avanços para a sociedade. A dificuldade de geração de energia por meio dos motores estacionários a diesel, incapazes de suprir a demanda, resultaram numa apropriação limitada dos benefícios proporcionados pela eletrificação. Neste sentido, as vantagens do acesso à energia elétrica, levantados por Ferreira (2013) e Capel (2015), não se configuravam de forma plena, na cidade, uma vez que a baixa geração se mostrava insuficiente para a iluminação pública dos bairros residenciais, e mesmo para a utilização consistente de eletrodomésticos; ademais, tal limitação representava um empecilho para o desenvolvimento industrial. A população, em grande parte migrante do estado de São Paulo, onde a eletrificação já era uma realidade, cobrava uma solução definitiva, que viria com a eletrificação de alta tensão da Usina de Salto Grande, substituindo assim a geração local.

\section{2ªsa (1962-1969): consolidação da COPEL e o alto custo do serviço}

Como já foi dito, o cenário de atuação da COPEL em Maringá, durante os primeiros anos da década de 1960, mostrava-se deficitário, com graves problemas tanto na geração como na distribuição da energia elétrica produzida, sendo frequentes, na cidade, os racionamentos e a falta de energia. Essa situação começa a mudar a partir de 1962.

Em meio à crise de geração na cidade, no início de 1961 chega, por meio do então diretor da COPEL, Pedro Viriato Parigot de Souza - que fica no posto até 1970 -, a notícia de que Maringá e região, enfim, teriam maior volume de energia elétrica disponível, oriunda da Usina Hidrelétrica de Salto Grande, pertencente à USELPA, a qual há tempos fazia o abastecimento de Londrina e municípios vizinhos. Para tanto, a COPEL já havia iniciado a instalação da rede de alta tensão, vinda de Londrina, e realizava concomitantemente a substituição dos postes de madeira por similares em concreto, nas cidades onde o serviço seria instalado. Para atender à demanda pelos postes de concreto, a empresa paulista Cavan, fornecedora dos mesmos, instalou uma unidade em Apucarana (RECCO, 2007).

Em 1962, é finalmente inaugurada em Maringá a subestação da COPEL, situada no Jardim Alvorada, contando com a participação do governador do estado, Ney Braga, e de outras autoridades locais. Tal fato é atestado na edição de O Jornal de Maringá, de 25 de março de 1962, que noticiava a inauguração da nova linha da COPEL, cujo funcionamento era exclusivamente para Maringá, sendo a potência instalada, de $4.800 \mathrm{Kw}$, suficiente para atender toda a cidade, o que tornou possível a paralisação total do fornecimento de energia pelos motores a diesel. A afirmação de Milton Santos $(2008$, p. 24) de que "O desenvolvimento da história vai de par com o desenvolvimento das técnicas", pois "A cada evolução técnica, uma nova etapa da história se torna possível", apoia-nos para afirmar que a instalação da subestação da COPEL, operando com energia advinda da Hidrelétrica de Salto Grande, representou uma nova para Maringá, pois eliminava o entrave da falta de energia ao desenvolvimento urbano. 
Sanada a questão da geração de energia, os trabalhos passam a se concentrar na estruturação da nova rede de distribuição no município. A primeira região atendida, como discorrem Cordovil e Barbosa (2015), foi a da Zona 1, pois se tratando do principal polo de comércio e serviços da cidade, foi essa porção que, historicamente, recebeu primeiro os melhoramentos de infraestrutura. De acordo com Dupuy (1998), em geral há uma forte relação entre a demanda e o estabelecimento das redes, pois é nos locais mais consolidados que estas encontram sua justificativa econômica e social para se estabelecerem. No caso de Maringá, nota-se que o fator econômico era predominante para a eletrificação, em razão da tendência de privilegiar o atendimento de grandes equipamentos na área central e em bairros de alta renda.

A primeira extensão do serviço se deu em 1961, em direção ao aeroporto, importante equipamento da época, beneficiando-se dessa extensão a Zona 3 (popular Vila Operária), que se encontra entre a Zona 1 e o aeroporto. $\mathrm{Na}$ sequência, ainda em 1961, o serviço se estrutura rumo à Zona 2, bairro residencial de alta renda e, em 1963, os serviços se deram em direção à Avenida 19 de Dezembro, ao Maringá Velho e à Zona 5 (CORDOVIL; BARBOSA, 2015). Essas extensões revelam a falta de neutralidade das ações do Estado com relação à instalação dos melhoramentos, que se concentravam nas porções do plano inicial projetado por Macedo Vieira, que eram as áreas de maior interesse econômico, ao passo que áreas de expansão, já bem conformadas na década de 1960, eram tratadas em segundo plano.

Assim, bairros como a Vila Santo Antônio, Jardim Alvorada e Vila Morangueira, mesmo sendo tecnicamente mais viáveis para receber a eletrificação, em razão da proximidade da subestação da COPEL, e apresentarem grau considerável de ocupação, foram preteridos em comparação às áreas de maior valor econômico. A densidade habitacional também não foi o fator determinante na extensão das redes, como pode ser visto no diagnóstico do CODEM de 1967, que aponta como áreas de maior densidade as Zonas 3 e 7, cuja densidade variava entre 96 a 160 hab./ha. Estas áreas, definidas no plano de Macedo Vieira como residencial operária, receberam os serviços posteriormente às zonas 1 e 2, cuja densidade variava entre 60 a 85 hab./ha. Em termos de adensamento construtivo, a área do plano inicial mostrava-se já consolidada, com exceção das zonas 5 e 6, abertas nos primeiros anos da década de 1960(Figura 5).

Neste sentido, confirma-se a visão deDupuy (1998), Castells (2005) e Milton Santos (2008), de relação de poder expressa pelas redes na sociedade capitalista, onde as evoluções técnicas são consumidas primeiramente pelos atores hegemônicos. Assim, as redes são a materialização, no território desta relação, pois ao mesmo tempo em que solidariza e conecta uma parcelada população ao serviço, exclui e marginaliza os que não Ihe têm acesso. Apesar do privilégio às áreas de maior valor econômico para o estabelecimento primeiro da eletrificação, com base no diagnóstico do CODEM (1967) podemos afirmar que, sanado o problema da geração de energia, a distribuição avançou na cidade de maneira rápida. O plano descreve:

A produção de energia elétrica na região atende perfeitamente à demanda, inexistindo perspectiva de insuficiência para qualquer setor de utilização. O progressivo crescimento do consumo é outro indicativo do desenvolvimento da área (CODEM, 1967, p.65). 
No entanto, o diagnóstico do CODEM (1967) também traz as constantes reclamações populares em relação ao alto custo das tarifas e aos métodos de medição de consumo, e afirma que, em certos bairros, devido ao elevado custo da ligação, que ficava a cargo do consumidor, a utilização da rede não chegava a $20 \%$, o que restringia o acesso ao serviço pela população de menor renda. A fim de mudar essa situação, a COPEL estudava um plano no qual seria feita a doação do medidor ao usuário, o que cortaria pela metade o custo da ligação e, consequentemente, possibilitaria maior utilização da rede (CODEM, 1967, p. 225).

Figura 5: Adensamento Construtivo - Maringá 1967

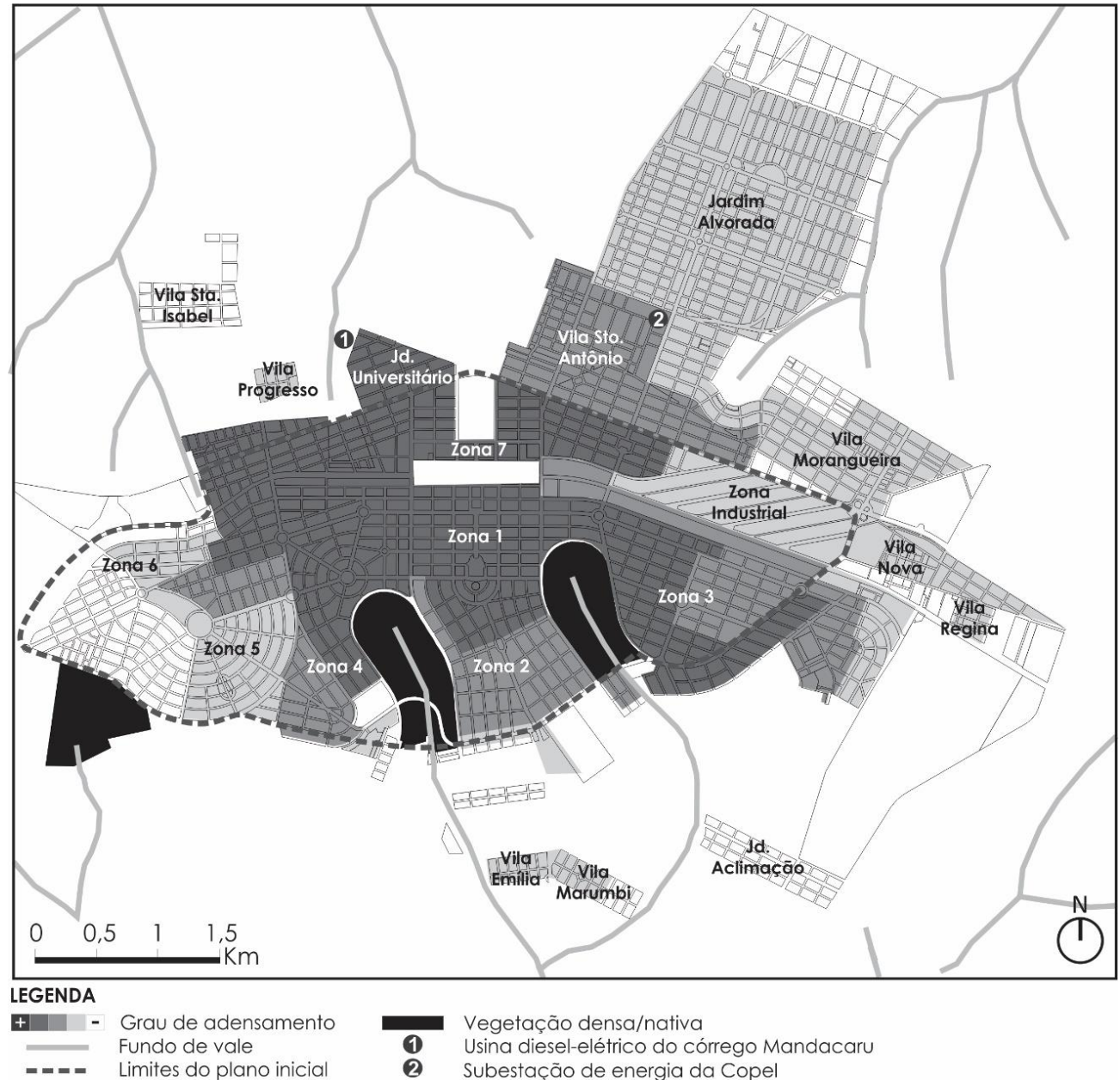

Fonte: CODEM,1967 (Prancha U4) - Adaptado pelos autores.

Relatos noticiados em O Jornal de Maringá confirmam o diagnóstico do CODEM (1967) e, além disso, apontam outros problemas como: constantes interrupções no serviço, devido a quedas de postes e fios; tarifas exorbitantes, instáveis, e leituras erradas. Em 5 de maio de 1967 foi publicada uma comparação com os serviços elétricos oferecidos pela vizinha Londrina, definindo seus serviços como de qualidade e com tarifa pela metade, enfatizando o fato de os serviços de eletricidade serem realizados por uma empresa privada; enquanto isso Maringá, servida pela COPEL, apresentava tarifas instáveis e com constantes interrupções no serviço (O Jornal de Maringá, 5 mai. 1967). Assim, aparentemente o setor privado ainda se apresentava como mais competitivo, no fornecimento da eletrificação, quando comparado à concessionária estadual. 
Devido às falhas cometidas pela COPEL na prestação de seus serviços, pela análise das reportagens é possível observar a relação instável entre a concessionária de energia e o poder municipal:

Câmara quer saber qual preço real do quilowatt ( $O$ Jornal de Maringá,18 mai. 1967).

Irregularidades cometidas pela COPEL ainda é assunto ( $O$ Jornal de Maringá, 1 jun. 1967).

COPEL impõe e prefeitura não reage: [...] determinou a formação de uma comissão de vereadores para verificar com a máxima urgência a situação entre a Prefeitura e Companhia Paranaense de Energia Elétrica (O Jornal de Maringá, 1 jun. 1967).

COPEL: Pedida comissão de inquérito (O Jornal de Maringá, 12 ago. 1967).

Prefeito critica a COPEL (O Jornal de Maringá, 13 ago. 1967).

Populares sem luz por má vontade da COPEL (O Jornal de Maringá, 13 set. 1967).

Em 5 de janeiro de 1968, O Jornal de Maringá apresentou ainda um levantamento realizado pela própria equipe, e um dossiê realizado pela Câmara de Vereadores da cidade, apontando para o preço abusivo cobrado pela COPEL pelo serviço de energia elétrica em Maringá, o dobro do cobrado em Londrina e Arapongas. As reclamações foram realizadas pelos moradores à prefeitura, havendo casos de moradores que pagaram NCR\$ 40,00 em novembro, saltando para NCR\$ 140,00 em dezembro, tendo consumido a mesma quantidade de energia. Na sessão "Opinião", do referido jornal, fora publicada uma convocação para que a população se mobilizasse, no intuito de buscar menores preços na tarifa abusiva, cobrada. Dentre os principais afetados pelo agravo, merecem destaque os moradores das casas populares da Vila Morangueira, cujas faturas sofriam constantes erros de leituras, interrupções de serviço, e alta no valor da energia. A Câmara de Vereadores instruíra esses populares a procurarem o órgão responsável, para resolver a questão.

Em 9 de janeiro de 1968, outra matéria discorre sobre os erros da COPEL, que resultam nos preços abusivos, cobrados pela mesma à população. Tais abusos são classificados em duas categorias: o aumento puro e simples das tarifas, sem aviso prévio, e erros nas leituras dos medidores. Destaca-se, na segunda categoria, o despreparo dos funcionários. Ademais, a falta de responsabilidade dos administradores e o possível caso de corrupção (caixa dois) são as causas apontadas, pela matéria, para as atitudes da COPEL (O Jornal de Maringá, 9 jan. 1968).

Ainda em 10 de janeiro de 1968, na sessão "Opinião", do mesmo jornal, o caso do preço abusivo das tarifas cobradas pela COPEL tem destaque. A matéria revela que, dentre os enganos da empresa, apenas $5 \%$ foram em favor do consumidor - valor que tem base na análise de contas de 100 usuários. A COPEL "é uma calamidade pública", enuncia o texto, que fomenta ainda as discussões sobre o papel não assumido pelos administradores públicos, de lutar pelos direitos da população frente aos abusos realizados pela empresa (O Jornal de Maringá, 10 jan. 1968). 
relatados dois casos de consumidores que foram alvo das atribulações da COPEL. O primeiro é de um consumidor que colocou um saquinho de sal de cozinha no medidor, o que fazia o mesmo girar mais vagarosamente, sendo que seu consumo no mês foi $80 \%$ menor; no entanto, nesse mesmo mês a empresa não realizou a leitura e sua conta foi calculada no "olhômetro". O segundo caso é de uma família da Vila Operária, que viajou durante todo o mês de dezembro, desligando todos os aparelhos consumidores de energia, mas que recebeu a conta de 36,00 cruzeiros novos.

Na reportagem intitulada "População aponta crimes da Copel", relatam-se novos casos de cobrança exorbitantes pela empresa que, segundo a matéria, "inventou" o sistema inédito de cobranças por estimativas. A dona de casa Maria Soares conta que sua conta de $\mathrm{NCr} \$ 25,00$ passou para $\mathrm{NCr} \$ 75,00$. O industrial Primo Monteschio descreve que Maringá poderá dar adeus às indústrias que desejavam se instalar na cidade. Ernesto Mieiro, proprietário de bar, mostra-se inconformado com o fato de que sua conta tenha passado de $\mathrm{NCr} \$ 70,00$ para NCr\$511,00 (O Jornal de Maringá, 18 jan. 1968). Em 23 de janeiro do mesmo ano, noticiavam-se novamente problemas com a cobrança da COPEL, desta vez em uma barbearia, cujo proprietário apontava o desligamento da energia, ou o fechamento do estabelecimento, como solução (O Jornal de Maringá, 23 jan. 1968).

A COPEL se manifestou contrária às denúncias, em 24 de janeiro de 1968, quando a matéria com a manchete "Copel diz que contas estão todas certas, certinhas..." destaca que um grupo de trabalho, formado pela Companhia, trabalhou para verificar as irregularidades das contas, e que "até agora, as contas apresentadas pelos consumidores foram examinadas e estão corretas e que as incorretas serão corrigidas" (O Jornal de Maringá, 24 jan. 1968). Um dia depois, 0 Jornal de Maringá (25. Jan. 1968) replicava a reportagem "Já que a Copel vê tudo certo, reclame na câmara contra as contas irregulares". A matéria destacava que o grupo de trabalho da empresa não vinha atendendo às expectativas e, por isso, "atendendo apelo deste jornal, o presidente da câmara, Kazumi Taguchi, determinou à comissão de vereadores encarregada de estudar o problema COPEL que colha as reclamações dos contribuintes que tenham sido vítimas da empresa energética".

Em 6 de fevereiro do mesmo ano, na sessão "Opinião", a matéria "Não esquecemos a Copel" discorre acerca do não abandono do caso, por parte do Jornal, e faz uma relação das indústrias necessárias, em Maringá, para atender ao mercado interno e quiçá realizar importações ao Paraguai e à Argentina, além de enfatizar a demanda por uma rede de energia eficaz para seu pleno funcionamento (O Jornal de Maringá, 6 fev. 1968) de fato, as críticas do periódico também se davam com relação ao entrave que o custo da tarifa impunha ao desenvolvimento do setor industrial. Afirmava-se que a COPEL impedia que indústrias se instalassem em Maringá, devido às altas taxas cobradas, que repeliam a instalação de indústrias e criavam um obstáculo para a implantação do parque industrial. É citada, como exemplo, a E. Englel Companhia Limitada, com sede em Canoas-RS, que pretendia se instalar em Maringá, não o tendo feito "por falta de condições viáveis, relativas aos preços das taxas de luz e força, cobrados pela Copel" (O Jornal de Maringá, 29 mar. 1968). 
os serviços prestados pela concessionária estadual. O custo do serviço ainda impunha dificuldades para o setor comercial e industrial, sendo também pouco acessível para a população de menor renda. Apesar disso, é notório um impacto positivo do estabelecimento da eletrificação na urbee na sociedade, com ganhos visíveis quanto à facilidade proporcionada pelos eletrodomésticos, a possibilidade de estabelecer uma vida noturna, e a ampliação da economia local por meio dos comércios, dependentes da energia e da vinda de indústrias. Após março de 1968, aparentemente as reclamações sobre o alto custo da tarifa e sobre o abuso na cobrança caem drasticamente. $O$ fato de $O$ Jornal de Maringá quase cessar suas críticas à COPEL deve ser visto com cautela, pois é sabido que os jornais, enquanto fonte primária de informação, não são um veículo isento de parcialidade.

Contudo, a análise mostra que, naquele momento, a geração e a rede de distribuição já estavam consolidadas em Maringá, e a COPEL ganhava força no âmbito estadual, onde já atuava em um número bastante expressivo de municípios, tendo sua rede de transmissão interligada com São Paulo e Santa Catarina e, brevemente, com o Paraguai, fato que contribuía com a industrialização do estado do Paraná (O Jornal de Maringá, 15 abr. 1969). Segundo dados de O Jornal de Maringá (29 jul. 1969), o crescimento das ligações industriais, apresentado pela COPEL, resultava numa média pouco inferior à de uma nova indústria por dia, e de acordo com publicação de 22 de agosto de 1969, do mesmo periódico, em, nos primeiros seis meses do ano o consumo de energia no Paraná teve um aumento de $20 \%$ em comparação ao mesmo período de 1968 , o que demostra maior popularização do serviço.

\section{CONSIDERAÇÕES FINAIS}

Nas primeiras décadas do século XX, a eletrificação já era questão resolvida, na capital paranaense e nas cidades próximas. Entretanto, nas porções de colonização mais recente do estado - como a porção Norte, onde se situa Maringá -, a energia elétrica demorou a se estabelecer, havendo a necessidade de medidas alternativas. Parte deste problema se deveu à configuração topográfica que, diferentemente do que ocorreu em Londrina, não possibilitou a viabilização de hidrelétricas locais no território de Maringá.

A solução encontrada foi a geração de energia por motores diesel-elétricos, tecnologia insuficiente para atender à demanda da cidade que crescia em ritmo acelerado, causando entraves ao seu desenvolvimento econômico e transtornos à população local. Assim, nos primeiros anos de funcionamento, a precariedade do serviço não propiciava o desenvolvimento de uma vida noturna, nem a popularização de facilidades domésticas, como os eletrodomésticos, contrastando assim com a modernidade expressa no plano urbanístico de Maringá.

É nesse contexto que, em 1956, a recém-criada COPEL assume, pela primeira vez, o serviço de distribuição de energia de um município do Estado: Maringá. A limitação na geração de energia, frente à demanda, refletiu-se em uma série de dificuldades técnicas e financeiras da companhia, no município. Mesmo ampliando os conjuntos diesel-elétricos, a geração de energia se mostrou insuficiente frente à demanda, o que levava à adoção de racionamentos frequentes, gerando a revolta da população, que cobrava do poder público uma 
solução definitiva.

A fase de geração dos motores diesel-elétricos perdurou até 1962, quando foi viabilizado o abastecimento de energia por uma linha de alta tensão, vinda da Usina Hidrelétrica de Salto Grande. Neste momento, a cidade de Maringá já se destacava como polo regional no estado do Paraná, apresentando expressiva taxa de crescimento populacional. Este evento marcou a superação do problema de geração da energia, iniciando a fase de estruturação da distribuição, a qual se considerou finalizada em 1969.

O processo de estruturação da nova rede de distribuição evidenciou a falta de neutralidade nas ações do Estado, que concentrava os melhoramentos nas zonas de maior interesse econômico, contidas na área planejada, deixando em segundo plano as áreas de expansão. Tal fato é reflexo da estruturação capitalista da sociedade, que coloca alguns atores urbanos em posição privilegiada, no consumo de bens e serviços. Consistindo em um inegável valor de uso, a eletrificação será então consumida, primeiramente, pelos setores de maior renda da cidade, para só depois se popularizar no espaço urbano.

Esta lógica de implantação das redes técnicas no espaço urbano corrobora com as análises deDupuy (1998), Castells (2005) e Milton Santos (2008), acerca da capacidade de tais redes expressarem relações de poder na sociedade. Para estes autores, os "conectores" -agentes com poder de decisão sobre o processo de implantação - são os detentores do poder, definindo a inclusão ou exclusão de acesso ao serviço, materializando, no território, desigualdades socioespaciais.

A segunda fase (1962-1969), marcada pela vinda da alta tensão da Usina de Salto Grande, representou um novo momento para a sociedade maringaense, permitindo, de maneira definitiva, o aproveitamento das comodidades proporcionadas pela eletricidade. Contudo, a relação conflituosa entre a população e a COPEL não cessou de imediato. Foram constantes as reclamações sobre o alto valor da tarifa e as inconsistências nas cobranças, apontando este fato como um entrave ao desenvolvimento do setor industrial. $\mathrm{O}$ alto custo gerava ainda certa elitização do serviço, pois ainda que a distribuição já atingisse grande parte do espaço urbano, no ano de 1967, bairros de menor renda ainda apresentavam baixos índices de utilização da rede. A comparação com a cidade de Londrina era frequente, destacando-se o fato de que a empresa privada, que a atendia, proporcionava um serviço de melhor qualidade e menor custo.

Aparentemente, a turbulenta relação entre a COPEL e a sociedade maringaense se encerra no fim da década de 1960, pois no ano de 1969 as constantes reclamações do serviço prestado pela concessionária do estado diminuem significativamente, noticiando-se inclusive um aumento constante do setor industrial na cidade. Deve-se ponderar, no entanto, que os jornais, enquanto fontes primárias de dados, não são uma fonte isenta parcialidade, podendo esta mudança, percebida, ser reflexo de acordos ou filiações políticopartidárias que não puderam ser aqui comprovados. Neste sentido, é importante ressalvar o cuidado de confrontamento dos dados, aqui apresentados, com outras fontes, tais como estudos locais (RECCO, 2007; CORDOVIL e BARBOSA, 2015), entrevistas com profissionais ligados à COPEL à época (SCHWABE, 2014), e diagnósticos técnicos da cidade (CODEM, 1967). 
problema solucionado, na urbe, superando assim o contraste observado entre a modernidade de seu plano urbanístico e a falta de serviços básicos para seu funcionamento, como a eletricidade. Neste momento a COPEL também se encaminhava para se tornar um ator hegemônico, na eletrificação do Paraná, controlando os serviços em diversas cidades, o que paulatinamente cessava a atuação de empresas privadas. Por todos os desafios e dificuldades impostas na administração do serviço elétrico em Maringá, a inserção pioneira da empresa, na cidade, constituiu uma rica experiência para a estruturação da concessionária estadual. 


\title{
The consolidation of electricity by Copel in Maringá, Brazil (1956-1969): Conflicts and repercussion on the region and the community
}

\begin{abstract}
The city of Maringá, Brazil, founded in 1947, was the result of a settlement plan by a colonizing company in the northern region of the state of Paraná, Brazil. Since the company failed to install the required infrastructure and the basic services in the area under analysis, the fast-growing town had to face several difficulties. Electricity was installed in 1956 when the recently founded Power Company of the State of Paraná (COPEL) was established in the municipality. Current analysis involves the COPEL's structure process in Maringá between 1956 and 1969, based on the implantation of electric power in the town and on its impact on the society of the period. Comparing and contrasting documental sources revealed that the installation of the state company occurred within a conflicting stance and had to overcome several impairments such as technical difficulties in power generation, rationing, network structure, critique of the service's high costs and people's and the authorities' pressure for better service. The COPEL's structure improved due to the difficulties it had to cope with. In fact, several years afterwards it would be the hegemonic agent in electric power in the state of Paraná.
\end{abstract}

KEY WORDS:Electric power; technical networks; urbanization. 


\section{REFERÊNCIAS}

BARBOSA, L. C. As redes técnicas sanitárias na estruturação do território: análise da cidade de Maringá-PR, entre 1947-1980. 2016. 345f. Tese (Doutorado em Arquitetura e Urbanismo), Instituto de Arquitetura e Urbanismo, Universidade de São Paulo, São Carlos, 2016.

BERGOC, G. J. A incorporação do espaço do norte do Paraná ao espaço nacional. 2012. 287p. Tese (Doutorado em Arquitetura e Urbanismo) - FAUUSP, São Paulo, 2012.

BRASIL. Código de Águas - Decreto $n^{\circ}$ 24.643, de 10 de Julho de 1934. Rio de Janeiro, 1934.

BRASIL. Decreto-Lei $n^{\circ} 1285$ de 18 de maio de 1939. Cria o Conselho Nacional de Águas e Energia e dá outras providências. Rio de Janeiro, 1939.

BRASIL. Lei Federal $n^{\circ}$ 6766, de 19 de dezembro de 1979, que dispõe sobre o parcelamento do solo urbano e dá outras providências. DF: Congresso Federal, 1979.

CAPEL, H. Discurso inaugural: Historia de laelectrificación mirando al futuro. Abertura do Terceiro Simpósio sobre a História da Eletrificação. Cidade do México, 2015.

CASTELLS, M. A Sociedade em Rede. vol. 1, 8 ed. São Paulo: Paz e Terra, 2005.

CODEM - COMISSÃO DE DESENVOLVIMENTO MUNICIPAL. Plano Diretor de Desenvolvimento de Maringá. Curitiba, 1967.

COMPANHIA MELHORAMENTOS NORTE DO PARANÁ - CMNP. Colonização e desenvolvimento do Norte do Paraná. Publicação comemorativa dos 50 anos da CMNP. São Paulo, 1975.

COPEL - Companhia Paranaense de Energia. História da energia no Paraná. 2016. Disponível

$<$ http://www.copel.com/hpcopel/root/nivel2.jsp?endereco=\%2Fhpcopel\%2Froot \%2Fpagcopel2.nsf\%2F0\%2F938F473DCEED50010325740C004A947F>. Acesso em: 19 de maio de 2015. 
CORDOVIL, F. C. de S.; ANDRADE, C. R. M. de. A cidade de Maringá, PR. O plano inicial e as requalificações urbanas. Scripta Nova (Barcelona), v. XII, p. 01-19, 2008.

CORDOVIL, F. C. de S.; BARBOSA, L. C. Dos lampiões na clareira à eletricidade: aspectos da formação da rede elétrica na cidade de Maringá, Paraná, Brasil, de 1942 a 1967. In: III Simposio Internacional. Historia de laelectrificación: estrategias y câmbios enel território y lasociedad, 2015, Ciudad de Mexico. Actasdel III Simposio Internacional Historia de laElectrificación. Estrategias y cambiosenelterritorio y lasociedad, 2015.

DEC/UEM - Laboratório de Aerofotogrametria. Levantamentos aerofotogramétricos de 1953 e 1963.

DUPUY, G. El urbanismo de las redes. Teorias y métodos. Barcelona: Oikos-Tau, 1998.

FERNANDO, M. Maringá Histórica: iniciativa pioneira em Maringá foi embriã da COPEL. Revista ACIM, maio de 2012.

FERREIRA, A. Urbanização, energia elétrica e a aceleração do cotidiano. In: ॥ Simpósio Internacional. Eletrificação e Modernização Social: a expansão da energia elétrica para a periferia do capitalismo, 2013, Barcelona. São Paulo: Universidade de São Paulo e Universidad de Barcelona/Geocrítica, 2013.

IBGE - INSTITUTO BRASILEIRO DE GEOGRAFIA E ESTATÍstICA. Censos demográficos, 1950, 1960 e 1970.

LUZ, F. O fenômeno urbano numa zona pioneira: Maringá. Maringá: Prefeitura Municipal, 1997.

MENDES, C. M. O edifício no jardim: um plano destruído. A verticalização de Maringá. 1992. 364 f. Dissertação (Mestrado em Geografia) - Faculdade de Filosofia, Letras e Ciências Humanas da Universidade de São Paulo, São Paulo, 1992.

MENEGUETTI, K. S. De cidade-jardim a cidade sustentável: potencialidades para uma estrutura ecológica urbana em Maringá-PR. 2007. 205p. Tese (Doutorado em Arquitetura e Urbanismo) - FAUUSP, São Paulo, 2007.

O JORNAL DE MARINGÁ, edições de (impressas): 23 jul. 1960; 29 jul. 1960; 11 dez. 1960; 7 fev. 1961; 11 fev. 1961; 21 fev. 1961; 18 nov. 1961; 21 nov. 1961; 25 mar. 1962; 5 mai. 1967; ,18 mai. 1967; 1 jun. 1967; 12 ago. 1967; 13 ago. 1967; 13 set. 
1967; 5 jan. 1968; 9 jan. 1968; 10 jan. 1968; 17 jan. 1968; 18 jan. 1968; 23 jan. 1968; 24 jan. 1968; 25. Jan. 1968; 29 mar. 1968; 15 abr. 1969; 29 jul. 1969; 22 ago. 1969 .

PARANÁ, Governo do Estado. Lei Estadual n¹384 de 10 de novembro de 1953. Institui o fundo de eletrificação e dá outras providências. Curitiba, 1953.

PARANÁ, Governo do Estado. Decreto n¹4.947 de 26 de outubro de 1954 - Dispõe sobre a organização de sociedade de economia mista sob a denominação de Companhia Paranaense de Energia Elétrica - COPEL e dá outras providências. Curitiba, 1954.

RECCO, R. Clareira flamejante. Maringá: Midiograf, 2007.

REGO, R. L.; MENEGUETTI, K. S. O território e a paisagem: a formação da rede de cidades no Norte do Paraná e a construção da forma urbana. Paisagem Ambiente: ensaios, n.25, p. 37-54, 2008.

SANTOS, M. Por uma outra globalização: do pensamento único à consciência universal. Rio de Janeiro: Record, 2008.

SCHWABE, A. E. Antonio Eriberto Schwabe: depoimento (nov. 2014). Entrevistadores: F. C. S. Cordovil e L. C. Barbosa. Gravação de áudio digital.

TARR, J. A. The evolution of the urban infrastructure in the Nineteenth and Twentieth Centuries. In: HANSON, Royce (ed.) Perspectives on Urban Infrastructure. Washington, D.C.: National Academic Press, 1984.

Recebido: 17 jun. 2018

Aprovado: 02 ago. 2018

DOI: $10.3895 /$ rbpd.v7n4.7046

Como citar: BARBOSA, L. C.; CORDOVIL, F. C. S.; SOUZA, T. M.; SAVARIS, M.; MASSA, S. A

consolidação da eletrificação pela Copel na cidade de Maringá-PR (1956-1969): conflitos e repercussão no território e na sociedade. R. bras. Planej. Desenv..Curitiba, v. 7, n. 4, p. 597-618, set./dez. 2018.Disponíve em: <https://periodicos.utfpr.edu.br/rbpd>. Acesso em: XXX.

Correspondência:

Leandro Cassimiro Barbosa

Av. Colombo, 5790 - Jd. Universitário - Maringá - PR, Brasil

Direito autoral: Este artigo está licenciado sob os termos da Licença CreativeCommons-Atribuição 4.0

Internacional.

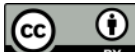

